\title{
Is There an Association Between Cortisol and Hypertension in Overweight or Obese Children?
}

\author{
Aleid JG Wirix ${ }^{1}$, Martijn JJ Finken ${ }^{2}$, Ines A von Rosenstiel-Jadoul ${ }^{3}$, Annemieke C Heijboer ${ }^{4}$, Jeroen Nauta ${ }^{5}$, Jaap W Groothoff ${ }^{6}$, \\ Mai JM Chinapaw ${ }^{1}$, Joana E Kist-van Holthe ${ }^{1}$ \\ ${ }^{1}$ VU University Medical Center, EMGO Institute for Health and Care Research, Department of Public and Occupational Health, Amsterdam, The \\ Netherlands \\ ${ }^{2} \mathrm{VU}$ University Medical Center, Department of Pediatric Endocrinology, Amsterdam, The Netherlands \\ ${ }^{3} \mathrm{MC}$ Slotervaart Hospital, Clinic of Pediatrics, Amsterdam, The Netherlands \\ ${ }^{4} \mathrm{VU}$ University Medical Center, Department of Clinical Chemistry, Endocrine Laboratory, Amsterdam, The Netherlands \\ ${ }^{5}$ Erasmus MC Sophia Children's Hospital, Clinic of Pediatric Nephrology, Rotterdam, The Netherlands \\ ${ }^{6}$ Emma Children's Hospital/Academic Medical Center, Department of Pediatric Nephrology, Amsterdam, The Netherlands
}

\section{What is already known on this topic?}

It is known that obesity can lead to hypertension. However, the precise mechanisms behind the development of hypertension in overweight or obese children are not yet completely understood.

\section{What this study adds?}

There is evidence for an increased cortisol production rate with decreased renal $11 \beta$-hydroxysteroid dehydrogenase 2 activity and flattening of early-morning peak cortisol and cortisone in overweight or obese children. There is no evidence for a role for cortisol in hypertension-induced obesity.

\section{Abstract}

Objective: The precise mechanisms behind the development of hypertension in overweight or obese children are not yet completely understood. Alterations in hypothalamic-pituitary-adrenal axis activity may play a role. We aimed to investigate the association between cortisol parameters and hypertension in overweight or obese children.

Methods: Random urine $(n=180)$ and early-morning saliva samples $(n=126)$ for assessment of cortisol and cortisone were collected from 1) hypertensive overweight children $(n=50), 2)$ normotensive overweight children ( $n=145)$, and 3) normotensive non-overweight children $(n=75)$.

Results: The age of participants was $10.4 \pm 3.3$ years and $53 \%$ were boys. The urinary cortisol-to-cortisone ratio $[\beta 1.11,95 \%$ confidence interval (CI) 1.05-1.19] as well as urinary cortisol/creatinine ( $\beta 1.38,95 \%$ CI 1.09-1.54), and cortisone/creatinine ratios ( $\beta 1.26$, $95 \%$ CI 1.17-1.36) were significantly higher in overweight or obese than in non-overweight children. After adjusting for body mass index-standard deviation score and urinary cortisone/creatinine ratio, but not cortisol/creatinine ratio, was significantly associated with presence of hypertension ( $\beta 1.12,95 \%$ CI 1.02-1.23). Salivary cortisol and cortisone levels were significantly lower in overweight or obese than in non-overweight children ( $\beta-4.67,95 \%$ CI -8.19- -1.15, and $\beta$ 0.89, $95 \%$ CI 0.80-0.97 respectively). There were no significant differences in cortisol parameters between hypertensive and normotensive overweight or obese children.

Conclusion: This study provided further evidence for an increased cortisol production rate with decreased renal $11 \beta$-hydroxysteroid dehydrogenase 2 activity and flattening of early-morning peak cortisol and cortisone in overweight or obese children. However, there were no significant differences in cortisol parameters between hypertensive and normotensive overweight and obese children.

Keywords: Hypertension, obesity, children, cortisol, pathophysiology 


\section{Introduction}

As a result of the growing overweight and obesity epidemic, hypertension is increasingly common, even in childhood; $4-14 \%$ of overweight children and $11-33 \%$ of obese children are diagnosed with hypertension $(1,2,3)$. Since both overweight and hypertension have a tendency to track from childhood into adulthood, these findings are of great concern $(4,5)$.

Establishing the cause of hypertension in obese children is of utmost importance for the development of therapeutic strategies. However, the pathophysiology of hypertension in obesity is complex and not fully understood (6). Several studies suggest that alterations in the production and/ or metabolism of glucocorticoids could play a role in the pathophysiology of the metabolic syndrome $(7,8)$, given its phenotypic similarities with Cushing's syndrome $(9,10)$. Glucocorticoids stimulate hepatic glucose production, lipolysis, vascular reactivity, and sodium reabsorption (11).

The tissue effects of glucocorticoids are for an important part regulated by $11 \beta$-hydroxysteroid dehydrogenase (11 $\beta$-HSD) isozymes, which interconvert cortisol with its inert metabolite cortisone. There are two isozymes. Type 1 generates cortisol from cortisone and is expressed mainly in liver and adipose tissue, and type 2 catalyses the reverse reaction primarily in the kidney. Pharmacological inhibition of renal $11 \beta$-HSD2 activity, e.g. by heavy use of liquorice, leads to hypertension by exposure of renal mineralocorticoid receptors to excess cortisol concentrations. The role of $11 \beta$-HSD type 1 in blood pressure regulation and hypertension is less well understood $(7,8,12)$.

There are few studies in children on $11 \beta$-HSD activity in obesity-induced hypertension $(12,13,14)$. One case study of four 10-to-15-year-old hypertensive obese boys found excess urinary adrenal androgen and cortisol metabolites (13). Another study in children aged 14 to 15 years, that made comparisons between obese children with $(n=15)$ and without hypertension $(n=11)$, and normotensive normalweight children $(n=15)$, found that the cortisol-to-cortisone ratio was higher in the hypertensive obese group than in the other two groups. Systolic blood pressure was positively associated with urinary tetrahydrocortisol (THF) $+5 \alpha-$ THF/ THE (allo-THF/tetrahydrocortisone) ratio, indicative of a cortisol/cortisone shuttle that favours cortisol (12). Another study found that serum adrenocorticotropic hormone (ACTH) and cortisol levels were positively associated with blood pressure in obese children aged 4 to 18 years, yet there was no control group. These results suggest that the hypothalamicpituitary-adrenal (HPA) axis is involved in the development of obesity-induced hypertension in children (14).
With the present study, we aimed to investigate if there is an association between cortisol parameters, including cortisol and cortisone in early-morning saliva and in random urine collections, and hypertension in overweight and obese children. To disentangle the contributions of hypertension and being overweight, we included two control groups, namely normotensive overweight and obese children and normotensive non-overweight children.

\section{Methods}

\section{Population and Design}

Non-fasting urine and early-morning fasting saliva samples were collected from a convenience sample of Dutch children aged 5 to 17 years, in the period between September 2013 and June 2015, consisting of: 1) $n=50$ overweight and obese children with hypertension, 2) $n=145$ overweight and obese children without hypertension, and 3) $n=75$ non-overweight children without hypertension. In total, 36 children provided both urine and saliva samples, 141 children provided only urine samples, and 90 children only saliva samples.

Overweight and obese children with and without hypertension were recruited at a pediatric outpatient obesity clinic and through their participation in our study on the prevalence of hypertension in overweight and obese children (15). The control group of healthy non-overweight children was recruited at a general pediatric outpatient clinic, which they visited for various reasons, and at two schools. Children with conditions that might affect blood pressure, for example a history of urinary tract infections, were not eligible for inclusion.

The study protocol has been approved by the VU University Medical Center Ethics Committee (approval nuber: A2015,121). Informed consent was obtained from at least one of their parents and from all children above the age of 12 years.

\section{Anthropometry and Blood Pressure Measurements}

Height was measured to the nearest 0.1 centimetre using a stadiometer. Body weight was measured to the nearest 0.1 kilogram using a digital balance scale with children barefooted and wearing light clothing. Body mass index (BMI) was calculated as weight in kilograms divided by the square of body height in meters and categorized according to the International Obesity Task Force (16).

Blood pressure was measured three consecutive times at the right arm after 5 minutes of rest in sitting position using an electronic oscillometric blood pressure device. An appropriate-sized cuff was used according to the guidelines 
of the National High Blood Pressure Education Program (NHBPEP) Working Group on Children and Adolescents (17). Based on the lowest of three consecutive blood pressure measurements, hypertension was defined as $\geq 95^{\text {th }}$ percentile for age, gender, and height (17).

\section{Urine and Saliva Sample Analyses}

Urine samples were collected on site. Early morning saliva samples were obtained using a Salivette ${ }^{\varpi}$ (Sarstedt AG \& Co. Nümbrecht, Germany) swap which was provided during the visit together with a return envelope. Participants were requested to obtain saliva immediately after awakening, between 06.00 and $09.00 \mathrm{a} . \mathrm{m}$. and prior to having breakfast and to return the sample by postal mailing.

Urine and saliva were stored at $-80{ }^{\circ} \mathrm{C}$. Both samples were analysed for cortisol and cortisone. $0.1 \mathrm{~mL}$ of urine or $0.1 \mathrm{~mL}$ of saliva was used to assess cortisol and cortisone concentrations, using an isotope dilution liquid chromatography-tandem mass spectrometry (LC-MS/ MS) method. Internal standards $\left({ }^{13} \mathrm{C}_{3}\right.$ labeled cortisol and cortisone) were added to the samples. Samples were extracted using supported liquid extraction (Isolute, Biotage, Uppsala, Sweden) and analysed by LC-MS/MS [Quattro Premier XE tandem mass spectrometer (Waters Corp., Milford, Massachusetts, USA)]. Lower limit of quantitation was $1.0 \mathrm{nmol} / \mathrm{L}$ for cortisol and $0.5 \mathrm{nmol} / \mathrm{L}$ for cortisone. The intra-coefficients of variation (CV\%) for cortisol were 7 and $4 \%$ at a level of 3 and $>5 \mathrm{nmol} / \mathrm{L}$, respectively, and for cortisone $<5 \%$ at all levels $>2.8 \mathrm{nmol} / \mathrm{L}$. The inter-CV\% was $<11 \%$ for both cortisol and cortisone.

\section{Outcome Measures}

Cortisol/creatinine ratio in spot urine is a measure of cortisol production (18). The urinary cortisol-to-cortisone ratio reflects renal $11 \beta$-HSD2 activity $(12,19)$. Cortisol and cortisone in early-morning saliva are indicators of the morning peak in HPA axis activity (20). The salivary cortisolto-cortisone ratio is only a rough estimate of the systemic interconversion between $11 \beta$-HSDs.

\section{Statistical Analysis}

BMI and height standard deviation scores (SDSs) were calculated using the LMS method (16), based on reference values from the World Health Organization (21) and Centers for Disease Control, respectively (22). Blood pressure SDSs were calculated using the equations provided by the NHBPEP Working Group (17). Differences in characteristics between hypertensive overweight and obese children, normotensive overweight and obese children, and normotensive non-overweight children were tested with ANOVA and post-hoc t-tests. Linear regression analysis was used to test associations with cortisol parameters between children with and without hypertension, adjusted for BMISDS, and between overweight and non-overweight children, adjusted for blood pressure SDS. Results are expressed as beta coefficients with $95 \%$ confidence intervals $(95 \% \mathrm{CI})$. A p-value $<0.05$ was considered statistically significant. The statistical analyses were performed with SPSS software version 22.0 (SPSS Inc., Chicago, Illinois).

\section{Results}

A total of 270 children and adolescents were included in the study. Urine samples were collected from 180 children (38 hypertensive overweight and obese children, 86 normotensive overweight and obese children, and 56 normotensive non-overweight children), and saliva samples from 126 children (17 hypertensive overweight and obese children, 64 normotensive overweight and obese children, and 45 normotensive non-overweight children). Demographic, anthropometric, and blood pressure data are presented in Table 1.

Salivary and urinary cortisol and cortisone, and cortisol-tocortisone ratios are displayed in Table 2 .

Salivary cortisol and cortisone levels, but not the salivary cortisol-to-cortisone ratio, were significantly lower in overweight or obese children than in non-overweight children ( $\beta$ 0.89, 95\% CI 0.80-0.97, and $\beta-4.67,95 \%$ CI -8.19- -1.15, respectively). There were no significant differences in these parameters between hypertensive and normotensive children. Salivary cortisol levels were not significantly associated with systolic ( $\beta$ 0.61, 95\% CI $0.31-1.21)$ or diastolic $(\beta 1.20,95 \%$ CI 0.74-1.97) blood pressure SDS.

Urinary cortisol/creatinine ( $\beta$ 1.38, $95 \%$ CI 1.09-1.54) and cortisone/creatinine ratios ( $\beta 1.26,95 \%$ CI 1.17-1.36), and the cortisol-to-cortisone ratio $(\beta 1.11,95 \%$ CI 1.05-1.19) were significantly higher in overweight or obese than in nonoverweight children. Urinary cortisol/creatinine ( $\beta 1.20,95 \%$ CI 1.06-1.36) and cortisone/creatinine ratios ( $\beta 1.19,95 \% \mathrm{CI}$ 1.08-1.30), but not the urinary cortisol-to-cortisone ratio ( $\beta$ $1.02,95 \% \mathrm{CI}$ 0.95-1.09), were higher in hypertensive children than in normotensive children. After adjustment for BMISDS, the association between urinary cortisol/creatinine ratio and hypertension was no longer significant $(\beta 1.11,95 \% \mathrm{CI}$ 0.97-1.25), but the association between cortisone/creatinine ratio and hypertension remained significant ( $\beta 1.12,95 \% \mathrm{CI}$ 1.02-1.23). After adjustment for BMI-SDS, urinary cortisol/ creatinine ratio was not significantly associated with systolic $(\beta 1.42,95 \%$ CI $0.91-2.21)$ or diastolic $(\beta 1.30,95 \%$ CI $0.94-$ 1.81) blood pressure SDS. 
Table 1. Characteristics of the study sample divided into hypertensive overweight, normotensiveoverweight, and normotensive non-overweight categories

\begin{tabular}{|c|c|c|c|}
\hline & $\begin{array}{l}\text { Hypertensive overweight } \\
\text { children }(n=50)\end{array}$ & $\begin{array}{l}\text { Normotensive overweight } \\
\text { children }(n=145)\end{array}$ & $\begin{array}{l}\text { Normotensive non-overweight } \\
\text { children }(\mathrm{n}=75)\end{array}$ \\
\hline Boys (\%) & $24(48)$ & $73(50)$ & $47(63)$ \\
\hline Age (yrs) & $10.0 \pm 3.5$ & $10.6 \pm 3.3$ & $10.4 \pm 3.0$ \\
\hline \multicolumn{4}{|l|}{ Weight } \\
\hline BMI (SDS) & $2.7 \pm 0.7^{\mathrm{a}}$ & $2.6 \pm 0.8^{b}$ & $-0.3 \pm 0.9$ \\
\hline Overweight n (\%) & $14(28)$ & $50(35)$ & - \\
\hline Obese n (\%) & $18(36)$ & $53(37)$ & - \\
\hline Mean systolic BP (SDS) & $1.98 \pm 0.44^{\mathrm{a}, \mathrm{c}}$ & $0.50 \pm 0.84^{b}$ & $0.11 \pm 0.89$ \\
\hline Mean diastolic BP (SDS) & $1.03 \pm 0.85^{\mathrm{a}, \mathrm{c}}$ & $0.23 \pm 0.62^{b}$ & $-0.09 \pm 0.68$ \\
\hline \multicolumn{4}{|c|}{ Values are shown as $\mathrm{n}(\%)$ or as mean \pm standard deviation } \\
\hline \multicolumn{4}{|c|}{${ }^{a} A$ significant difference between hypertensive overweight and normotensive non-overweight children $(p<0.001)$} \\
\hline \multicolumn{4}{|c|}{${ }^{\mathrm{b}} \mathrm{A}$ significant difference between normotensive overweight and non-overweight children $(\mathrm{p}<0.001)$} \\
\hline \multicolumn{4}{|c|}{${ }^{\mathrm{C}} \mathrm{A}$ significant difference between hypertensive overweight and normotensive overweight children $(\mathrm{p}<0.001)$} \\
\hline \multicolumn{4}{|c|}{ Weight is categorised according to the definition of the International Obesity Task Force (24) } \\
\hline \multicolumn{4}{|c|}{ BMI: body mass index, BP: blood pressure, SDS: standard deviation score } \\
\hline
\end{tabular}

Table 2. Salivary and urinary levels of cortisol and cortisone and cortisol/cortisone ratios in the subjects classified as hypertensive overweight, normotensive overweight, and normotensive non-overweight

\begin{tabular}{|c|c|c|c|}
\hline & $\begin{array}{l}\text { Hypertensive } \\
\text { overweight children }\end{array}$ & $\begin{array}{l}\text { Normotensive } \\
\text { overweight children }\end{array}$ & $\begin{array}{l}\text { Normotensive } \\
\text { non-overweight children }\end{array}$ \\
\hline Saliva samples & $n=17$ & $n=64$ & $n=45$ \\
\hline sCortisol (nmol/L) & $5.0(3.7-9.5)$ & $5.9(3.9-7.7)^{\mathrm{a}}$ & $7.4(5.0-10.7)$ \\
\hline sCortisone (nmol/L) & $22.0(18.3-29.0)$ & $23.5(17.3-30.0)^{\mathrm{a}}$ & $28.0(23.0-34.0)$ \\
\hline sCCR & $0.24(0.17-0.32)$ & $0.26(0.20-0.31)$ & $0.27(0.20-0.32)$ \\
\hline Urine samples & $n=38$ & $n=84$ & $\mathrm{n}=56$ \\
\hline uCortisol/cr (nmol/mmol) & $10.9(6.7-31.7)^{\mathrm{b}}$ & $11.0(7.2-17.3)^{\mathrm{c}}$ & $5.1(3.4-9.3)$ \\
\hline uCortisone/cr (nmol/mmol) & $31.2(22.5-43.0)^{\mathrm{b}}$ & $27.7(19.1-35.1)^{\mathrm{c}}$ & $13.6(11.6-20.6)$ \\
\hline uCCR & $0.40(0.23-0.55)$ & $0.42(0.34-0.52)^{\mathrm{c}}$ & $0.32(0.25-0.51)$ \\
\hline \multicolumn{4}{|c|}{ Values are shown as median (interquartile range) } \\
\hline \multicolumn{4}{|c|}{ aA significant difference between normotensive overweight and non-overweight children $(p<0.05)$} \\
\hline \multicolumn{4}{|c|}{${ }^{\mathrm{b} A}$ significant difference between hypertensive overweight and normotensive non-overweight children $(\mathrm{p}<0.001)$} \\
\hline \multicolumn{4}{|c|}{${ }^{c} \mathrm{~A}$ significant difference between normotensive overweight and non-overweight children $(p<0.001)$} \\
\hline CCR: cortisol/cortisone ratio, $\mathrm{cr}=$ creatinine & & & \\
\hline
\end{tabular}




\section{Discussion}

This study provided evidence for an increased renal excretion of free cortisol and cortisone, with higher excretion of cortisol relative to cortisone, in overweight or obese children. It also showed that early morning salivary levels of cortisol and cortisone were lower in overweight or obese children. However, there were no differences in cortisol parameters between hypertensive and normotensive overweight or obese children.

The findings from this study confirm previous observations $(20,23)$ that childhood obesity is associated with an increased cortisol production rate, decreased renal $11 \beta$-HSD2 activity, and flattening of early-morning peak cortisol and cortisone. We found no significant differences in cortisol parameters between hypertensive and normotensive overweight or obese children. This is in contrast to previous studies in obese children which showed a positive association of systolic blood pressure, as part of metabolic syndrome, with increased serum levels of cortisol and ACTH (14,24), and in free cortisol in 24-hr urine (25). An explanation for the lack of an association with hypertension in our study is that the groups of hypertensive and normotensive overweight or obese children might have been too similar regarding presence of features of metabolic syndrome, as an index of glucose tolerance was not tested, to be able to detect differences in cortisol parameters.

In the total sample of overweight and non-overweight children, we found significant associations between ratios of urinary cortisol or cortisone to creatinine and the presence of hypertension. However, after adjustment for BMI-SDS, both associations became weaker, and only the association with urinary cortisone/creatinine ratio remained significant.

Future studies should elucidate whether hypertensive and normotensive overweight or obese children differ in the metabolism of cortisol. Cortisol is metabolized reversibly by $11 \beta$-HSDs and irreversibly by A-ring reductases and CYP3A4. In adults, impaired metabolic clearance of cortisol has been implicated to play a role in metabolic disease susceptibility (26).

A major strength of our study is inclusion of three study groups consisting of hypertensive overweight and obese children, normotensive overweight and obese children, and normotensive non-overweight children. This approach enabled us to study the relative contributions in overweight or obesity and hypertension. Another strength is the method we used to measure cortisol and cortisone concentrations. LC-MS/MS is known to be a very accurate, specific and sensitive method to measure steroid hormones $(27,28)$.

\section{Study Limitations}

Our study has several limitations. First, hypertension was based upon blood pressure measurements obtained on only one occasion, although three times consecutively. No 24hour ambulatory blood pressure monitoring was performed to confirm the diagnosis of hypertension. Second, for practical reasons, only random daytime urine samples (with unspecified sampling times) were collected instead of 24hr urine, although cortisol/creatinine ratio in spot urine has proven to be a reliable tool for the assessment of cortisol production (18). Third, only early-morning saliva samples were collected, so that association with diurnal rhythmicity in HPA axis activity could not be tested. Cortisol in scalp hair - as an index of long-term glucocorticoid exposure - was not tested in our sample, although recent studies have shown strong associations with indices of obesity (29). Yet another limitation is the cross-sectional study design of our study. A longitudinal study is necessary to gain insight into temporal relations. Ideally, the role of cortisol in the development of obesity-induced hypertension should be studied in a prospective cohort study with participants being sampled prior to developing overweight.

\section{Conclusion}

We found that overweight and obese children had an increased cortisol production rate. Furthermore, overweight and obesity were associated with a higher urinary cortisol-tocortisone ratio, reflecting decreased renal $11 \beta$-HSD2 activity, as well as with lower levels of early-morning cortisol and cortisone. However, there were no significant differences in cortisol parameters between hypertensive and normotensive overweight and obese children. More research is needed to elucidate whether cortisol metabolism is involved in the pathogenesis of obesity-induced hypertension in children.

\section{Acknowledgements}

This study was supported by the Dutch Kidney Foundation (VR 12.03). The authors would like to thank all children and their parents for their cooperation. In addition, the authors thank the schools, the staff of the pediatric outpatient obesity clinic of the MC Slotervaart Hospital, the staff of the General Pediatric Outpatient Clinic of the VU University Medical Center, and the Child Health Care professionals for their assistance with the recruitment and data collection.

\section{Ethics}

Ethics Committee Approval: The study was approved by the VU University Medical Center Ethical Committee.

Informed Consent: Informed consent was obtained from 
at least one parent, and from all children above the age of 12 years.

Peer-review: Externally peer-reviewed.

\section{Authorship Contributions}

Concept: Martijn JJ Finken, Jeroen Nauta, Jaap W Groothoff, Joana E Kist-van Holthe, Design: Joana E Kist-van Holthe, Martijn JJ Finken, Data Collection or Processing: Aleid JG Wirix, Ines A von Rosenstiel-Jadoul, Martijn JJ Finken, Laboratory Analysis: Annemieke C Heijboer, Analysis or Interpretation: Aleid JG Wirix, Mai JM Chinapaw, Joana E Kist-van Holthe, Martijn JJ Finken, Literature Search: Aleid JG Wirix, Writing: Aleid JG Wirix, Martijn JJ Finken, Ines A von Rosenstiel-Jadoul, Annemieke C Heijboer, Jeroen Nauta, Jaap W Groothoff, Mai JM Chinapaw, Joana E Kist-van Holthe.

Financial Disclosure: This study was funded by the Dutch Kidney Foundation (VR12.03).

\section{References}

1. Sorof JM, Lai D, Turner J, Poffenbarger T, Portman RJ. Overweight, ethnicity, and the prevalence of hypertension in school-aged children. Pediatrics 2004;113:475-482.

2. Maldonado J, Pereira T, Fernandes R, Carvalho M. Blood pressure distribution of a sample of healthy Portuguese children and adolescents: the AVELEIRA registry. Rev Port Cardiol 2009;28:1233-1244.

3. Polat M, Yıkılkan H, Aypak C, Görpelioğlu S. The relationship between BMI and blood pressure in children aged 7-12 years in Ankara, Turkey. Public Health Nutr 2014;17:2419-2424. Epub 2014 May 22

4. Chen X, Wang Y. Tracking of blood pressure from childhood to adulthood: a systematic review and meta-regression analysis. Circulation 2008;117:3171-3180. Epub 2008 Jun 16

5. Singh AS, Mulder C, Twisk JW, van Mechelen W, Chinapaw MJ. Tracking of childhood overweight into adulthood: a systematic review of the literature. Obes Rev 2008;9:474-488. Epub 2008 Mar 5

6. Wirix AJ, Kaspers PJ, Nauta J, Chinapaw MJ, Kist-van Holthe JE. Pathophysiology of hypertension in obese children: a systematic review. Obes Rev 2015;16:831-842. Epub 2015 Jun 22

7. Chapman K, Holmes M, Seckl J. 11 $\beta$-hydroxysteroid dehydrogenases: intracellular gate-keepers of tissue glucocorticoid action. Physiol Rev 2013;93:1139-1206

8. Schnackenberg CG, Costell MH, Krosky DJ, Cui J, Wu CW, Hong VS, Harpel MR, Willette RN, Yue TL. Chronic inhibition of $11 \beta$ -hydroxysteroid dehydrogenase type 1 activity decreases hypertension, insulin resistance, and hypertriglyceridemia in metabolic syndrome. Biomed Res Int 2013;2013:427640. Epub 2013 Mar 18

9. Walker BR. Cortisol--cause and cure for metabolic syndrome? Diabet Med 2006;23:1281-1288.

10. Morton NM. Obesity and corticosteroids: 11 beta-hydroxysteroid type 1 as a cause and therapeutic target in metabolic disease. Mol Cell Endocrinol 2010;316:154-164. Epub 2009 Oct 3

11. Walker BR. Glucocorticoids and cardiovascular disease. Eur J Endocrinol 2007;157:545-559.
12. Csábi GY, Juricskay S, Molnár D. Urinary cortisol to cortisone metabolites in hypertensive obese children. J Endocrinol Invest 2000;23:435-439.

13. Paize F, Isherwood D, Honour J, Jones CA. Abnormal urinary steroid profiles in four hypertensive obese children. J Pediatr Endocrinol Metab 2010;23:237-244.

14. Prodam F, Ricotti R, Agarla V, Parlamento S, Genoni G, Balossini C, Walker GE, Aimaretti G, Bona G, Bellone S. High-end normal adrenocorticotropic hormone and cortisol levels are associated with specific cardiovascular risk factors in pediatric obesity: a cross-sectional study. BMC Med 2013;11:44.

15. Wirix AJ, Nauta J, Groothoff JW, Rabelink TJ HiraSing RA, Chinapaw MJ, Kist-van Holthe JE. Is the prevalence of hypertension in overweight children overestimated? Arch Dis Child 2016;101:998-1003. Epub 2016 Mar 31

16. Cole TJ, Lobstein T. Extended international (IOTF) body mass index cut-offs for thinness, overweight and obesity. Pediatr Obes 2012;7:284294. Epub 2012 Jun 19

17. National High Blood Pressure Education Program Working Group on High Blood Pressure in Children and Adolescents. The fourth report on the diagnosis, evaluation, and treatment of high blood pressure in children and adolescents. Pediatrics 2004;114(2 Suppl):555-576.

18. Kapoor N, Job V, Jayaseelan L, Rajaratnam S. Spot urine cortisolcreatinine ratio - A useful screening test in the diagnosis of Cushing's syndrome. Indian J Endocrinol Metab 2012;16 (Suppl 2):376-377.

19. Stewart PM, Whorwood CB, Walker BR. Steroid hormones and hypertension: the cortisol-cortisone shuttle. Steroids 1993;58:614-620.

20. Kjölhede EA, Gustafsson PE, Gustafsson PA, Nelson N. Overweight and obese children have lower cortisol levels than normal weight children. Acta Paediatr 2014;103:295-299. Epub 2013 Dec 30

21. de Onis M, Onyango AW, Borghi E, Siyam A, Nishida C, Siekmann J. Development of a WHO growth reference for school-aged children and adolescents. Bull World Health Organ 2007;85:660-667.

22. Centers for Disease Control and Prevention National Center for Health Statistics. CDC growth charts: United States 2000. Retrieved October 2014, from www.cdc.gov/growthcharts.

23. Björntorp P, Rosmond R. Hypothalamic origin of the metabolic syndrome X. Ann N Y Acad Sci 1999;892:297-307.

24. Sen Y, Aygun D, Yilmaz E, Ayar A. Children and adolescents with obesity and the metabolic syndrome have high circulating cortisol levels. Neuro Endocrinol Lett 2008;29:141-145.

25. Reinehr T, Kulle A, Wolters B, Knop C, Lass N, Welzel M, Holterhus PM. Relationships between 24-hour urinary free cortisol concentrations and metabolic syndrome in obese children. J Clin Endocrinol Metab 2014;99:2391-2399.

26. Walker BR, Andrew R. Tissue production of cortisol by 11 betahydroxysteroid dehydrogenase type 1 and metabolic disease. Ann N Y Acad Sci 2006;1083:165-184.

27. Ackermans MT, Endert E. LC-MS/MS in endocrinology: what is the profit of the last 5 years? Bioanalysis 2014;6:43-57.

28. Vogeser M, Parhofer KG. Liquid chromatography tandem-mass spectrometry (LC-MS/MS)--technique and applications in endocrinology. Exp Clin Endocrinol Diabetes 2007;115:559-570.

29. Veldhorst MA, Noppe G, Jongejan MH, Kok CB, Mekic S, Koper JW, van Rossum EF, van den Akker EL. Increased scalp hair cortisol concentrations in obese children. J Clin Endocrinol Metab 2014;99:285290. Epub 2014 Jan 1 